CONF- $9502120--2$

UCRL-JC-118990

PREPRINT

\title{
Reducing Polarization Dependence in Asymmetric Coupler Wavelength Filters Using Birefringence Compensation
}

\author{
R.J. Deri \\ M.A. Emanuel \\ F.G. Patterson \\ S.P. Dajaili
}

RECEIVED

APR 121996

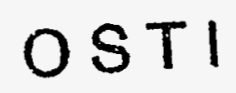

This was prepared for submittal to the

Integrated Photonics Research

Dana Point, CA

February 23-25, 1995

October 1994
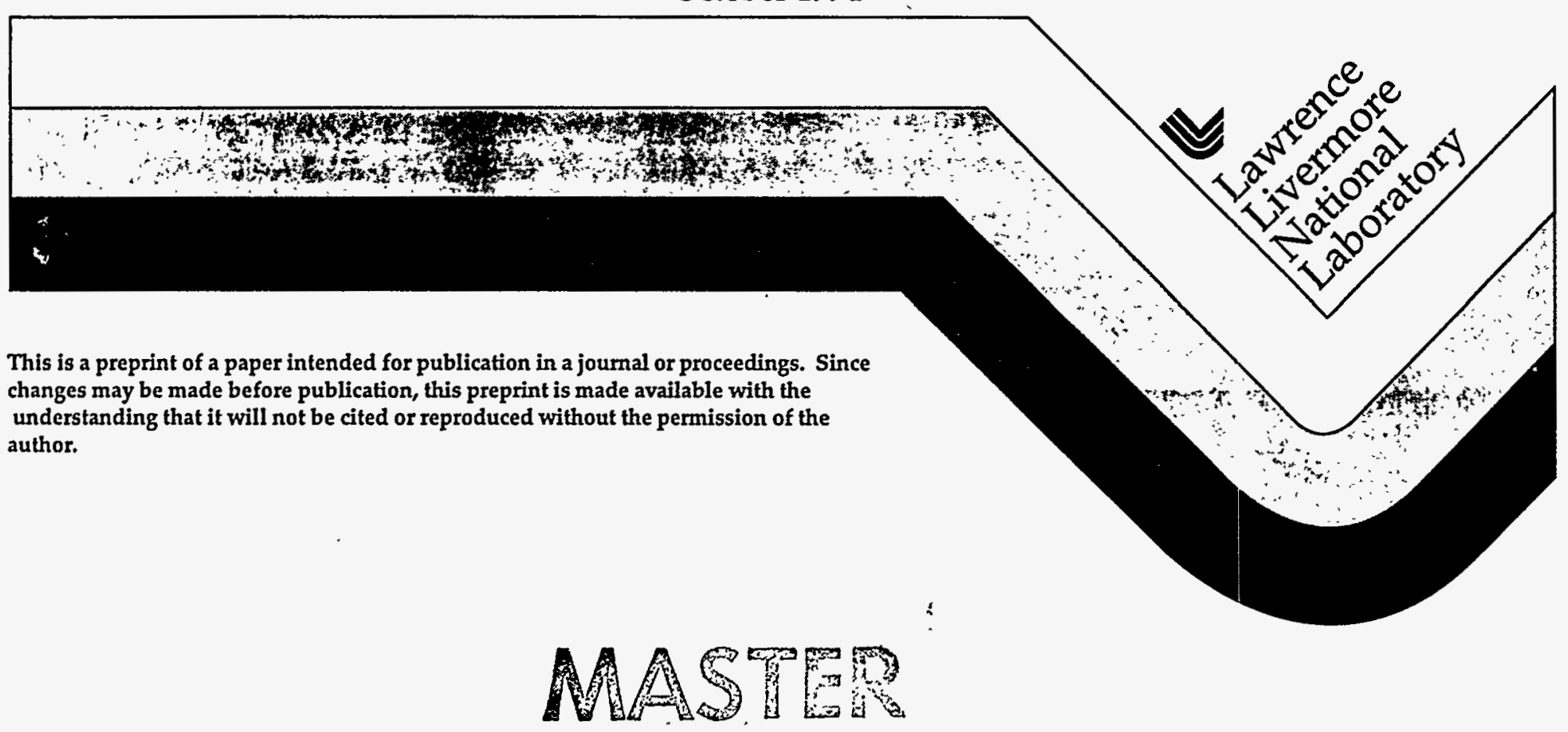

$\rightarrow$ mant.

DISTRMUTIDN OF THS DOCHIENT 6 LAUMTED 


\section{DISCLAIMER}

This document was prepared as an account of work sponsored by an agency of the United States Government. Neither the United States Government nor the University of California nor any of their employees, makes any warranty, express or implied, or assumes any legal liability or responsibility for the accuracy, completeness, or usefulness of any information, apparatus, product, or process disclosed, or represents that its use would not infringe privately owned rights. Reference herein to any specific commercial product, process, or service by trade name, trademark, manufacturer, or otherwise, does not necessarily constitute or imply its endorsement, recommendation, or favoring by the United States Government or the University of California. The views and opinions of authors expressed herein do not necessarily state or reflect those of the United States Government or the University of California, and shall not be used for advertising or product endorsement purposes. 


\section{DISCLAIMIER}

Portions of this document may be illegible in electronic image products. Images are produced from the best available original document. 


\title{
REDUCING POLARIZATION DEPENDENCE in ASYMMETRIC COUPLER WAVELENGTH FILTERS using BIREFRINGENCE COMPENSATION
}

\author{
R. J. Deri, M. A. Emanuel, F.G. Patterson, and S.P. Dijaili \\ Lawrence Livermore National Laboratory \\ PO Box 808, Livermore, CA 94550
}

\begin{abstract}
We demonstrate that a novel birefringence compensation technique can reduce the polarization dependence of AlGaAs directional coupler wavelength filters operating at $\lambda=773 \mathrm{~nm}$.
\end{abstract}




\title{
REDUCING POLARIZATION DEPENDENCE in ASYMMETRIC COUPLER WAVELENGTH FILTERS using BIREFRINGENCE COMPENSATION
}

\author{
R. J. Deri, M. A. Emanuel, F.G. Patterson, and S.P. Dijaili \\ Lawrence Livermore National Laboratory, Livermore, CA 94550
}

WDM systems are creating demand for wavelength demultiplexers to extract a single wavelength channel from a stream of multi-wavelength data. A popular filter design employs an asymmetric directional coupler, either with or without a grating inserted between two coupled waveguides (fig. 1).[1-5]. This device selects a single wavelength channel, determined by the phase matching condition for the two coupled waveguides. Several such filters have been demonstrated using vertical couplers on III$V$ semiconductors, because this approach enables precise control of waveguide thicknesses and indices as well as monolithic integration.[2-5] Recently, integration of these filters with photodetectors and/or optical amplifiers [6-8] was demonstrated for receiver applications. A major obstacle to using such chips is the polarization sensitivity of the asymmetric coupler. Polarization-dependent shifts in filter wavelength $\Delta \lambda_{0}$ exceed the filter bandwidth,[2-6] resulting in extreme polarization sensitivity $\Delta \lambda_{0} \approx 30 \mathrm{~nm}$ incompatible with conventional single-mode fiber communications. The only reported polarization-insensitive device of this type[9] employs a doubly-periodic grating, and cannot be used in couplers without a grating. We previously proposed a birefringence compensation technique to eliminate polarization dependence in devices either with or without grating-assisted coupling, and used simulations to show that the approach involves fabrication tolerances.[10] Here we report the first experimental demonstration of these devices, validating the design concept proposed in ref. [10].

The polarization dependence of vertical asymmetric couplers on GaAs or InP results from the intrinsic waveguide birefringence, most of which occurs in the narrower waveguide. We replace the thicker waveguide core with a multiple quantum well (MQW), designed so the MQW birefringence compensates the upper guide birefringence.[10] Achieving practical tolerances requires additional design strategies to be presented at the conference. Based on these rules, we fabricated the AlGaAs filter of fig. 1 , in which all cladding layers are $\mathrm{Al}_{0.5} \mathrm{Ga}_{0.5} \mathrm{As}$, the upper waveguide core consists of $0.1 \mu \mathrm{m} \mathrm{Al} \mathrm{D}_{2.2} \mathrm{Ga}_{0.8}$ As sandwiched between two $0.09 \mu \mathrm{m}$ compositionally graded layers, and the bottom waveguide core comprises an $\mathrm{Al}_{0 .}{ }_{2} \mathrm{Ga}_{0.8} \mathrm{As} / \mathrm{Al} \mathrm{l}_{0.5} \mathrm{Ga}_{0.5} \mathrm{As}$ MQW. with well:barrier thicknesses of $158 \dot{A}: 159 \AA$ (nominal). These epitaxial layers were grown by low-pressure MOCVD on a 2-inch GaAs wafer. The Al0.2 Ga0.8As composition was verified using room temperature photoluminescence $(\lambda-P L=722.7 n m$, Al mole fraction within \pm 0.02 ). Thickness values were verified by SEM, which are shown in fig. 1. The principal difference between design and realized values are reduced upper guide thickness $(0.23$ vs. $0.28 \mu \mathrm{m})$. Fabrication involved wet etching to remove the upper waveguide layer, followed by dry etching to define a rib guide input to the chip. The devices consist of an input rib waveguide using the lower (MQW) guiding layer, which uptapers to launch a broad beam into a $100 \mu \mathrm{m}$ wide directional coupler section. 


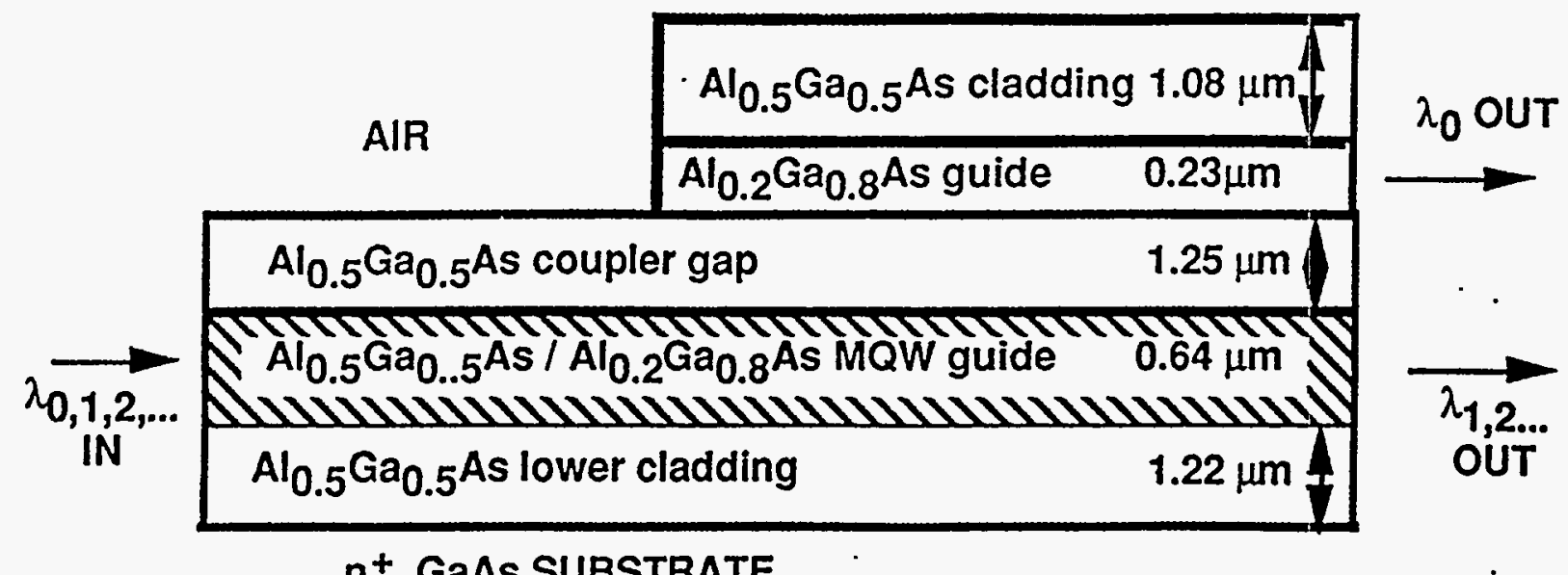

$n^{+}$GaAs SUBSTRATE

Fig. 1: Device schematic. Graded interfaces in the upper waveguide are not shown.

Devices were tested using a tunable Ti:sapphire laser. The filter spectral response. was obtained by imaging its nearfield output onto a slit (fig. 2) using a 0.65NA objective, and monitoring the output intensity in a single waveguide vs. wavelength.

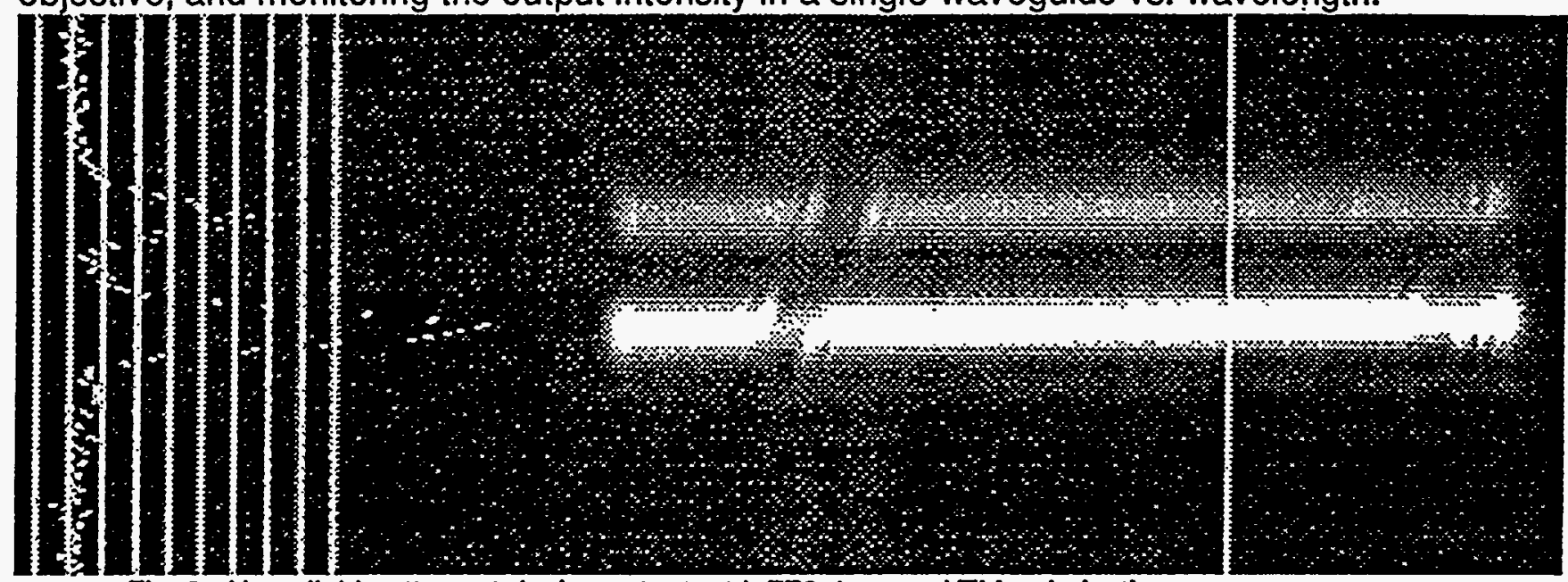

Fig. 2: Near-field pattern at device output, at $l=773.4 \mathrm{~nm}$ and TM polarization.

The video trace is linear in optical intensity, with measured peak-to-peak separation of $1.79 \mu \mathrm{m}$.

Our filters operate near $\lambda_{0}=773 \mathrm{~nm}$ with the response shown in fig. 3 . They exhibit a bandwidth $\approx 1 \mathrm{~nm} F W H M$ and a polarization dependence $\Delta \lambda_{0}=\lambda_{0} \mathrm{TE}-\lambda_{0} \mathrm{TM}$ from -1.8 to $-2.1 \mathrm{~nm}$ (fig. 3) over a $2 \times 3 \mathrm{~cm}^{2}$ area. This result demonstrates appreciable reduction in polarization dependence compared to the $\Delta \lambda_{0} \approx+30 \mathrm{~nm}$ of conventional devices.[2-5] In fact, the birefringence is overcompensated in our devices $\left(\Delta \lambda_{0}<0\right.$, whereas $\Delta \lambda_{0} \gg>0$ for conventional devices) due to the residual lattice mismatch of AlGaAs on GaAs, which was not considered in the device design. Mismatch-induced strain causes piezo-optic birefringence in AlGaAs,[11] which is calculated to cause $\Delta \lambda_{0}=-1.5 \mathrm{~nm}$ for this device. Our results also show that birefringence compensation can work uniformly over large areas. The filter polarization dependence $\Delta \lambda_{0}$ remains constant within $\pm 0.15 \mathrm{~nm}$ over centimeter lengths, even though the filter wavelength $\lambda_{0}$ varies by $\approx 2 \mathrm{~nm}$ over a $1 \mathrm{~cm}$ displacement. 
Fig. 3: Filter response for a $3.86 \mathrm{~mm}$ long coupler. TE and TM response amplitudes are not drawn to the same scale.

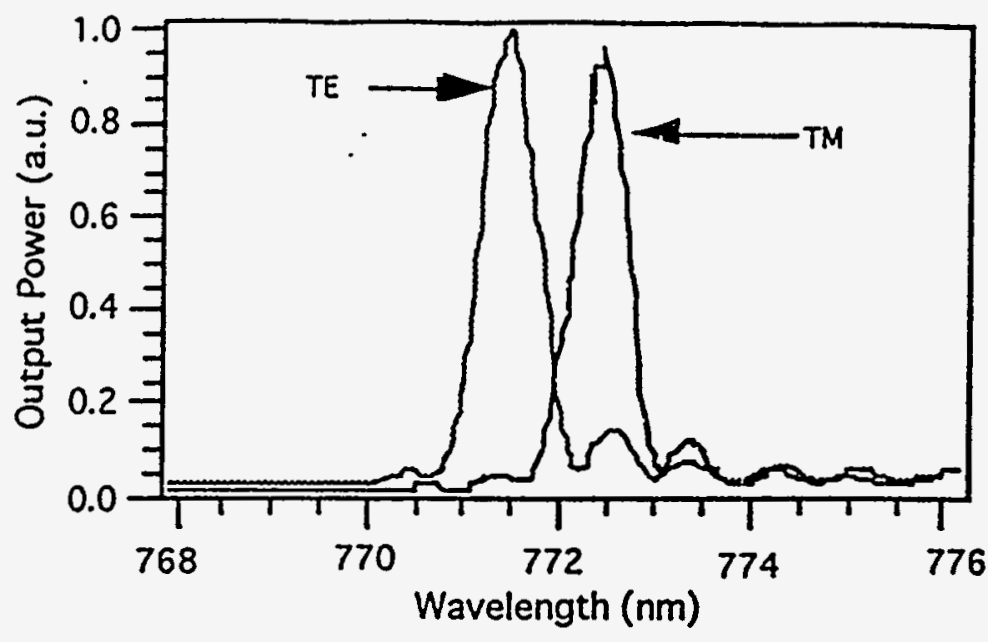

Because the upper waveguide is thinner than designed, our filter operated at shorter wavelengths (design value $\lambda_{0}=830 \mathrm{~nm}$ ), which increases the mode confinement and thus coupler beat length. Simulations show that longer beat lengths are polarization-sensitive. Our devices confirm this prediction, exhibiting beat lengths of 17 , $11 \mathrm{~mm}$ for TE, TM polarization respectively, in close quantitative agreement with theory. Simulations also indicate that shorter beat lengths (below $5 \mathrm{~mm}$ ) are polarizationinsensitive. Thus, we expect that our filter could be rendered polarization-insensitive within $1 \mathrm{~dB}$ by reducing the coupler gap layer thickness (to $\approx 1.0 \mu \mathrm{m}$ ), which would result in polarization-insensitive amplitude response and $=5 \mathrm{~nm}$ filter bandwidths.

In conclusion, we have shown that birefringence compensation can reduce the polarization-dependent wavelength shift in AIGaAs asymmetric directional couplers to $\approx 2 \mathrm{~nm}$ with a high degree of uniformity. Designs accounting for material strain should achieve $\approx 0.5 \mathrm{~nm}$ shifts, indicating that our approach will enable polarization-insensitive WDM filters with bandwidths of a few nanometers. Both uniformity measurements and simulations[10] show that polarization-insensitive filter wavelengths can be achieved over large areas with practical tolerances. Moderate control of filter wavelength and coupler beat length must be exercised to achieve polarization-insensitive amplitude response. Our approach can also be applied to InGaAsP devices operating at longer wavelengths, and to grating assisted asymmetric couplers. It should thus solve the polarization dependence problem for a variety of commonly employed WDM channel filters suitable for integrated receivers.

*This work was performed under the auspices of the U.S. Department of Energy by Lawrence Livermore National Laboratory under contract No. W-7405-Eng-48.

Belerences: 1. R.C. Alferness and R.V. Schmidt, Appl. Phys. Lett. 33, 161 (1978).

2. B. Broberg, B.S. Lindgren, et al., J. Lightwave Technol. 4, 196 (1986).

3. C. Wu, C. Rolland, et al., Photonics Technol. Lett. 3, 519 (1991).

4. R.C. Alfemess, T.L. Koch et al., Appl. Phys. Lett. 55, 2012 (1993).

5. H. Sakata, S. Takeuchi, et al., Photonics Technol. Lett. 3,899 (1991).

6. H. Sakata and H. Kawasaki, Appl. Phys. Lett. 64, 1201 (1994).

7. Z.M. Chuang, M.J. Mondry, et al., Appl. Phys. Lett. 63, 880 (1993).

8. I. Kim, R.C. Alferness, et al., Photonics Technol. Lett. 5, 1319 (1993).

9. F. Heismann, L.L. Buhl, et al., Appl. Phys. Lett. 64, 2335 (1994).

10. R.J. Deri, F.G. Patterson, et al, Proc. Europ. Conf. Opt. Commun. 1, 415 (1994).

11. S. Adachi and K. Oe, J. Appl. Phys. 54,6620 (1983). 